\section{Kidney \\ Blood Pressure Research}

Kidney Blood Press Res 2018;43:1273-1284

DOI: 10.1159/000492409

Published online: 3 August, 2018

2018 The Author(s)

Published by S. Karger AG, Basel

www.karger.com/kbr

\title{
Pharmacological Signatures of the Exenatide Nanoparticles Complex Against Myocardial Ischemia Reperfusion Injury
}

\author{
Yi Zhang Ping Qian Hong Zhou Ruilin Shen Bo Hu Yajun Shen \\ Xiaofang Zhang Xiaohua Shen Guangtao Xu Limin Jin
}

Department of Pathology, Molecular Medicine Center, Jiaxing Hospital of Traditional Chinese Medicine, Jiaxing University, Jiaxing, P.R.China

\section{Key Words}

Exenatide - Nanoparticle $\cdot$ Myocardial ischemia reperfusion injury $\cdot$ GLP-1 - Heart function • PLL-PEG-PLL

\begin{abstract}
Background/Aims: Myocardial ischemia/reperfusion (I/R) injury (MI/RI) is a critical cause of death in patients with heart disease. However, the pharmaco-therapeutical outcome for MI/RI remains unsatisfactory. Innovative approaches for enhancing drug sensitivity and recovering myocardial function in MI/RI treatment are urgently needed. The purpose of this study was to evaluate the protective effects of exenatide-loaded poly(L-lysine)-poly(ethylene glycol)poly(L-lysine) (PLL-PEG-PLL) nanoparticles (NPs) against MI/RI. Methods: The size of PLLPEG-PLL NPs and the loading and release rates of exenatide were determined. The in vitro NP cytotoxicity was evaluated using newborn rat cardiomyocytes. Rats pretreated with free exenatide or exenatide/PLL-PEG-PLL polyplexes were subjected to 0.5 - $h$ ischemia and 2-h reperfusion in the left anterior descending coronary artery. The histopathologic lesions were assessed using hematoxylin-eosin staining. The general physiological indices, including blood pressure (BP), heart rate (HR), the left ventricular ejection fraction (LVEF) and end-diastolic pressure (LEVDP), and the left ventricular pressure maximal rate of rising $\left(\mathrm{dp} / \mathrm{dt}_{\max }\right)$, were monitored using a non-invasive blood pressure analyzer and color Doppler echocardiography. The antioxidative activity in the myocardial tissue was measured. The myocardial enzymatic activity was further estimated by determining the serum levels of creatine kinase (CK), lactate dehydrogenase (LDH), cardiac troponin T (cTnT), and glucagon-like peptide-1 (GLP-1), as well as the expression of GLP-1R in the myocardial tissue. Results: Exenatide preconditioning attenuated the oxidative stress injury and promoted the myocardial function in I/R-induced myocardial injury, while the application of block copolymer PLL-PEG-PLL as a potential exenatide nanocarrier with sustained release significantly enhanced the bioavailability of
\end{abstract}

Y. Zhang and P. Qian contributed equally to this study and therefore shared the first authorship. 


\section{Kidney Blood Pressure Research}

Zhang et al.: Exenatide Nanoparticles For MI/RI

exenatide. Conclusion: The block copolymer PLL-PEG-PLL may function as a potent exenatide nanocarrier for augmenting pharmacotherapy against MI/RI with unprecedented clinical benefits. Further study is needed to better clarify the underlying mechanisms.

(C) 2018 The Author(s)

Published by S. Karger AG, Basel

\section{Introduction}

Myocardial ischemia-reperfusion (I/R) injury (MI/RI) as a common pathophysiological entity of cardiovascular diseases is one of the leading causes of death worldwide [1,2]. Lipid peroxidation, reactive oxygen species (ROS) production, apoptosis, and DNA/RNA injury are reported to be associated with MI/RI [3]. If these factors are not purged, they may ultimately induce a high incidence of chronic heart failure [4-6]. Hence an increasing number of cardiologists are interested in the strategies to reduce MI/RI, including medical treatment, surgical intervention, and gene therapy [7-9]. Glucagon-like peptide-1 (GLP-1) is an incretin hormone modulating glucose homeostasis $[10,11]$. Recent research has demonstrated that GLP-1 can also play an important role in cardiovascular physiology [12]. Previous studies showed that GLP-1 may protect the brain and gastrointestinal tract against I/R through several signaling pathways $[13,14]$.

Exenatide as the agonist of GLP-1 is reported to have anti-inflammatory and antioxidant stress effects by regulating blood glucose, blood lipids and blood pressure, and a cardiovascular protective effect by ameliorating myocardial infarction and heart failure [15-17]. Recent studies have shown that exenatide may attenuate MI/RI via modulating cardiomyocyte metabolism [18-20]. In addition, exenatide could exert a cardioprotective effect by improving the mitochondrial function in an in-vitro model of hypoxia/reoxygenation (H/R) [21]. Pretreatment with exenatide may decrease abnormalities of myocardial cell mitochondrial and reduce oxidative stress, and enhance ATP synthesis and mitochondrial ATPase activity in myocardial cells subjected to H/R [21]. However, the half-life of exenatide in circulating blood is short as 9.5 hours, which limits its clinical application because of the need for frequent injections [22].

It is therefore an urgent task to innovate more effective strategies for enhancing the drug sensitivity and myocardial function in the treatment of MI/RI. To overcome the limitation of exenatide in therapeutic application, we developed a poly(L-lysine)-poly(ethylene glycol)poly(L-lysine) (PLL-PEG-PLL) polyplex as an exenatide nanocarrier, which is composed of a linear PEG block polymer and two brush-like PLL block polymers by combining the positively charged PLL brush block polymer with the negatively charged exenatide through electrostatic interactions at $\mathrm{pH} 7.4$ for the sake of enhancing the circulation life of exenatide in vivo, and prolonging the pharmacological effect of exenatide/PLL-PEG-PLL nanoparticles in protecting the heart against I/R-induced myocardial injury.

\section{Materials and Methods}

Synthesis of PLL-PEG-PLL

PLL-PEG-PLL was synthesized by using the previously described method [23-26].

Briefly, poly( $\varepsilon$-benzyoxycarbonyl-L-lysine)-poly(ethylene glycol)-poly( $\varepsilon$-benzyoxycarbonyl-L-lysine) (PZLL-PEG-PZLL) was firstly synthesized by dissolving and stirring $\mathrm{H}_{2} \mathrm{~N}-\mathrm{PEG}-\mathrm{NH}_{2}$ (Sigma-Aldrich, USA) with $\mathrm{N}, \mathrm{N}$-dimethylformamide (DMF) at $\mathrm{pH} 7.4$ at $37^{\circ} \mathrm{C}$ for $6 \mathrm{~h}$. The benzyl groups of PZLL were then deprotected in the presence of bromine hydride $(\mathrm{HBr})$, trifluoroacetic acid $\left(\mathrm{CF}_{3} \mathrm{COOH}\right)$, and acetic acid $\left(\mathrm{CH}_{3} \mathrm{COOH}\right)$ to obtain the final product PLL-PEG-PLL, as depicted in Fig. 1.

Cytotoxicity assay of PLL-PEG-PLL

A 3-(4, 5-dimethylthiazol-2-yl)-2, 5-diphenyltetrazolium bromide (MTT) colorimetric assay [27-32] was performed to assess the cytotoxic effects of PLL-PEG-PLL. Briefly, the heart from 2-day-old newborn rats 


\section{Kidney Blood Pressure Research}

was removed, rinsed by D-Hanks solution (Solarbio, Beijing), and then cut into pieces of 1 $\mathrm{mm}^{3}$ in the primary myocardial cell essential medium (PMEM) (PriCells, Wuhan) supplemented with $0.25 \%$ trypsin. It was then incubated at $37^{\circ} \mathrm{C}$ for $10 \mathrm{~min}$, and subsequently centrifuged at $1,000 \mathrm{rpm}$ for $10 \mathrm{~min}$ to harvest the cells. After 2-h culturing, fibroblasts adhering to the wall were gentlyblown to the medium. All the medium supernatants were centrifuged at 3,000 rpm for $5 \mathrm{~min}$, and the supernatant

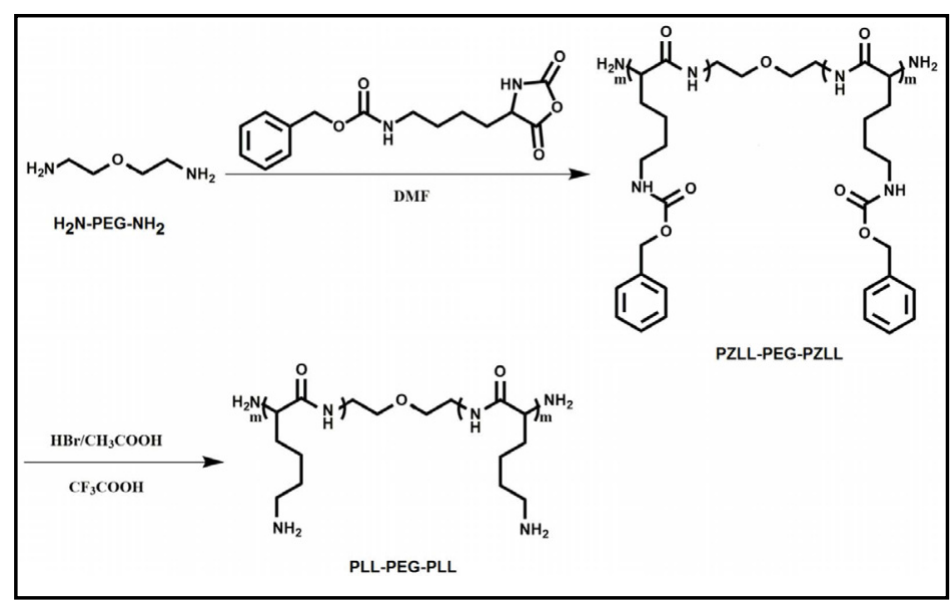

Fig. 1. Synthesis of PLL-PEG-PLL. was discarded. The contractile cardiomyocytes were obtained by adding PMEM containing $10 \%$ calf serum and bromodeoxyuridine (BrdU, $10 \mathrm{mM}$ ). The obtained cardiomyocytes were identified with anti-myoglobin antibody and anti- $\alpha$-striated muscle sarcomere actin ( $\alpha$-SCA) antibody by immunohistochemical method. The acquired cardiomyocytes were seeded at a density of $5 \times 10^{5} / \mathrm{L}$ cells per well in a 96-well poly-D-lysine-coated plate and maintained in PMEM supplemented with $10 \%$ fetal bovine serum (FBS) and $1 \%$ penicillin-streptomycin (P/S) at $37^{\circ} \mathrm{C}$ in a humidified incubator with $5 \% \mathrm{CO}_{2}$. The cells were treated with a concentration gradient of PLL-PEGPLL diluted with normal saline $(0.9 \%)$, and then cultured at $37^{\circ} \mathrm{C}$ for $24 \mathrm{~h}$. To determine the cell viability, the wells were added with MTT $(20 \mu \mathrm{L})$, and then treated with ethanol-dimethyl sulfoxide (DMSO) (1:1, $100 \mu \mathrm{L}$ ) to solubilize the dark blue crystals of MTT formazan completely ( $20 \mathrm{~min})$. The absorbance or optical density (OD) of per well at $570 \mathrm{~nm}$ was measured on a microplate multimode reader (Turner Biosystems, USA). The blank control was taken from wells without cells, which were also cultured with the MTT. Cells incubated in the wells without polymers were used as a negative control. PLL-PEG-PLL was used as a potential cytotoxicity sample. The percentage of relative cell viability was calculated by comparing the value of treated cells with that of untreated cells using the following equation: $\left(O D_{\text {sample }}-O D_{\text {blank }}\right) /\left(O D_{\text {cells }}{ }^{-}\right.$ $\left.\mathrm{OD}_{\text {blank }}\right) \times 100 \%[29]$.

\section{Encapsulation and in vitro release of exenatide in PLL-PEG-PLL}

To assess the encapsulation of exenatide by PLL-PEG-PLL, a certain amount of exenatide $(5 \mathrm{mg} / \mathrm{mL})$ in phosphate buffered solution (PBS) (0.01 mM, pH 7.4) was mixed with PLL-PEG-PLL in PBS, in which the mixed solution was dialyzed in a dialysis tubing (MWCO, $100 \mathrm{kDa}$ ). The dialysis of free exenatide in PBS was performed under the same conditions to serve as controls. When the free exenatide in the control experiment was completely dialyzed, the quantification of exenatide in the outer dialysate of the polymer solution was measured using the enzyme-linked immunosorbent assay (ELISA) (Roche, Germany) according to the manufacturer's instructions. The exenatide/PLL-PEG-PLL copolymers were characterized with a nanoparticle size analyzer and transmission electron microscope (TEM). Exenatide release from exenatide/ PLL-PEG-PLL was measured using a dialysis method (MWCO, $100 \mathrm{kDa}$ ) at $37^{\circ} \mathrm{C}$ with $5 \mathrm{~mL}$ of exenatide/PLLPEG-PLL against a PBS (0.1 M, pH 7.4) at the set time intervals. Finally, the released exenatide was quantified by ELISA according to the manufacturer's instruction.

\section{Evaluation of the exenatide concentration in circulating blood and blood glucose test}

Exenatide ( $5 \mu \mathrm{g} / \mathrm{kg}$ body weight [bw]) or exenatide/PLL-PEG-PLL ( $99.8 \mu \mathrm{g} / \mathrm{kg}$ bw, containing $5 \mu \mathrm{g} /$ $\mathrm{kg}$ exenatide [based on loading capacity of nanoparticle]) was administered by abdominal subcutaneous injection to Sprague-Dawley male rats weighing 170-190 g. At 0.02-, 0.04-, 0.08-, 0.17-, 0.25-, 0.33-, 0.42-, 0.5, 0.67-, 0.75-, 1-, 1.5-, 1.67-, 1.75-, 2-, 2.5-, and 3-day time interval, $0.2 \mathrm{~mL}$ blood was extracted and separated immediately by centrifugation at $12,000 \times \mathrm{g}$ at $4^{\circ} \mathrm{C}$ for $10 \mathrm{~min}$ to harvest the serum. The concentration of 


\section{Kidney Blood Pressure Research}

Zhang et al.: Exenatide Nanoparticles For MI/RI

exenatide and exenatide/PLL-PEG-PLL in rat blood was detected using a double-antibody sandwich ELISA kit. Blood glucose levels were measured using the glucose oxidase-peroxidase (GOD-POD) methods [33].

\section{Animals and the surgical process of $M I / R I$}

Male Sprague-Dawley rats weighing 170-190 g were obtained from the Laboratory Animal Unit of Jiaxing University (Jiaxing, China). All experimental procedures were approved by the Ethics Committee for Animal Care and Use at Jiaxing University. A total of 50 rats were generally anesthetized by intraperitoneal (i.p.) injection with $1 \%$ pentobarbital sodium ( $50 \mathrm{mg} / \mathrm{kg} \mathrm{bw}$ ), and then equally randomized into five groups: 1) sham-operated group (Sham group), where rats were only treated with separation of the left anterior descending coronary artery at $2 \mathrm{~mm}$ on the lower margin of the left atrial appendage; 2) I/R group, where $\mathrm{I} / \mathrm{R}$ was induced by clamping the left anterior descending coronary artery located at a 2-mm distance from the lower margin of the left atrial appendage for $0.5 \mathrm{~h}$, followed by $2 \mathrm{~h}$ reperfusion; 3) exenatide + I/R group (Exenatide group), where the rats were pretreated subcutaneously with exenatide (5 $\mu \mathrm{g} / \mathrm{kg}$ bw) in the abdomen at $30 \mathrm{~min}$ prior to the I/R procedure, and subsequently dosed daily for 6 days; 4) PLL-PEG-PLL + I/R group (P group), where PLL-PEG-PLL (94.8 $\mu \mathrm{g} / \mathrm{kg} \mathrm{bw}$ ) was administrated at $30 \mathrm{~min}$ prior to the I/R procedure, and subsequently dosed daily for 6 days; and 5) exenatide/PLL-PEG-PLL + I/R group (Exenatide/P group), where exenatide/P (99.8 $\mu \mathrm{g} / \mathrm{kg}$ bw [containing $5 \mu \mathrm{g} / \mathrm{kg}$ bw exenatide]) was administrated at 30 min prior to the I/R procedure, and subsequently dosed on 3-day intervals.

\section{General monitoring of the rat physiological index}

The coronary blood flow (CBF) was measured with a color Doppler echocardiograph (GE, USA). A greater than $90 \%$ reduction in $\mathrm{CBF}$ of the left anterior descending coronary artery was confirmed during the vessel occlusion before reperfusion [29]. The parameters of the left ventricular ejection fraction (LVEF), the left ventricular end-diastolic pressure (LVEDP), and the left ventricular pressure maximal rate of rising $\left(+\mathrm{dp} / \mathrm{dt}_{\max }\right)$ were monitored with a pressure probe connecting the cardiac catheter in the left ventricle being from the right common carotid artery by the color Doppler echocardiograph. The heart rate (HR) and blood pressure (BP) were monitored through the caudal artery using a Non-invasive Blood Pressure Analyzer (Visitech, USA).

\section{ELISA assay}

Blood was collected at $120 \mathrm{~min}$ after reperfusion, and centrifuged at $12,000 \times g$ at $4^{\circ} \mathrm{C}$ for $10 \mathrm{~min}$ to harvest the serum. The resected rat myocardial tissue was homogenized in protein lysate buffer in icecold normal saline and then centrifuged to harvest the supernatant. The serum levels of creatine kinase (CK), lactate dehydrogenase (LDH), cardiac troponin T (cTnT) and glucagon-like peptide-1 (GLP-1), as well as the levels of superoxide dismutase (SOD) and malondialdehyde (MDA) in the myocardial tissue, were measured with the double-antibody sandwich ELISA kits (Abcam, Shanghai) according to the manufacturer's instructions.

\section{Histopathological assessment in the myocardial tissue}

The heart tissue was fixed in 4\% neutral PBS/paraformaldehyde, paraffin-embedded, sliced into 4- $\mu \mathrm{m}$ sections, and stained with hematoxylin \& eosin (HE) staining. The histopathological changes were examined under an optical microscope (Leica, Germany) and graded according to the degree of damage based on the percentage of involvement of the myocardium [2,34]. The damage quantification from 10 areas corresponding to the myocardial tissue was graded using the following parameters: cellular edema, cell apoptosis, necrocytosis, hemorrhage, and myocardial fiber twisting and fracture based on a four-score system ( 0 , histopathological changes $\leq 10 \% ; 1,=11-25 \% ; 2,=26-50 \% ; 3,=51-75 \%$; and 4, =76-100\%). The mean score for each parameter was calculated and subjected to statistical analysis.

\section{Immunohistochemistry}

The 4- $\mu \mathrm{m}$ myocardial tissue paraffin sections were deparaffinized, rehydrated, and treated with $3 \%$ hydrogen peroxide $\left(\mathrm{H}_{2} \mathrm{O}_{2}\right)$ to remove endogenous peroxidase. Then they were incubated with the primary anti-GLP-1 receptor (anti-GLP-1R) antibody (Abcam, Shanghai) overnight at $4^{\circ} \mathrm{C}$. The secondary antibody 


\section{Kidney Blood Pressure Research}

was horseradish peroxidase-labeled streptavidin. Microphotographs were taken with Leica DM2000LED imaging system.

\section{Western blotting analysis}

Western blotting analysis was performed following previous reports [35-37]. Briefly, the rat myocardial tissue was homogenized in protein lysate buffer. An equal amount of homogenate protein was subjected to $10 \%$ sodium dodecyl sulfate-polyacrylamide gels (SDS-PAGE) and then electrophoretically transferred to the nitrocellulose membrane. After blocking with 5\% skim milk in Tris-buffered saline (TBS)-Tween 20 (TBST) for $1 \mathrm{~h}$, the membrane was immunoblotted with primary anti-GLP-1R antibody at $4^{\circ} \mathrm{C}$ overnight and treated with alkaline phosphatase-conjugated secondary antibody. Blots were stained via $\beta$-actin antibody. The products were visualized and analyzed using enhanced chemiluminescence and FluorChem system (Thermo, USA).

\section{Statistical analysis}

Data are expressed as the mean \pm standard deviation (Mean \pm SD). Microsoft Excel 2016 database and GraphPad Prism 5 software were used to record and analyze all the data. Statistical differences were determined using Student's $t$-test or one-way analysis of variance (ANOVA) with posthoc test. A value of less than $0.05(\mathrm{p}<0.05)$ in a two-tailed test was considered statistically significant.

\section{Results}

\section{Synthesis and characterization of PLL-PEG-PLL}

The PLL-PEG-PLL nanoparticles were composed of a linear PEG block and two brushlike PLL blocks. The synthesis route and structure of PLL-PEG-PLL are demonstrated in Fig. 1. The molecular weight of PLL-PEG-PLL was $15.5 \mathrm{kDa}$ (obtained from ${ }^{1} \mathrm{H} \mathrm{NMR}$ ) (Fig. 2A). The images of PLL-PEG-PLL and exenatide/PLL-PEG-PLL polymer were observed by TEM. They displayed an orbicular structure with a diameter of $31 \mathrm{~nm}$ and $77 \mathrm{~nm}$ respectively (Fig. 2B, Table. 1).

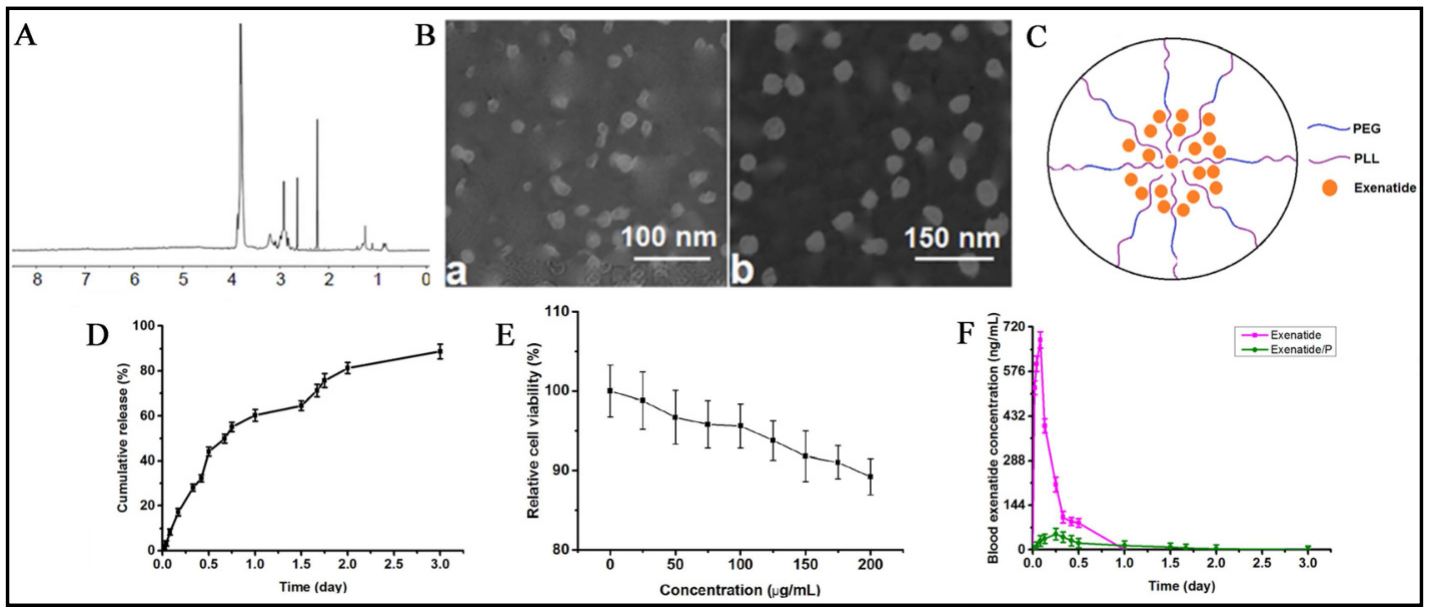

Fig. 2. Characterization of PLL-PEG-PLL and exenatide/PLL-PEG-PLL. Notes: (A) ${ }^{1} \mathrm{H}$ NMR spectra of PLLPEG-PLL; (B) TEM images of PLL-PEG-PLL (Ba) and exenatide/PLL-PEG-PLL (Bb); (C) Encapsulation of exenatide by the block copolymer PLL-PEG-PLL; (D) The cumulative releasing profile of exenatide/PLLPEG-PLL (n=5); (E) Relative cellular viability of rat cardiomyocytes cultured with different concentrations of PLL-PEG-PLL (n=5); (F) Blood concentrations of free exenatide and exenatide from exenatide/PLL-PEGPLL $(n=5)$. 


\section{Kidney Blood Pressure Research}

Kidney Blood Press Res 2018;43:1273-1284

\begin{tabular}{l|l}
\hline DOI: $10.1159 / 000492409$ & (C) 2018 The Author(s). Published by S. Karger AG, Basel
\end{tabular}

Published online: 3 August, 2018 www.karger.com/kbr

Zhang et al.: Exenatide Nanoparticles For MI/RI
Encapsulation of exenatide in and release of exenatide from PLL-PEGPLL

Exenatide was efficiently loaded by the copolymer PLL-PEG-PLL at physiological $\mathrm{pH}$ through hydrophobic interaction between the negatively charged exenatide (the isoelectric point of exenatide is 4.86) and the positively charged PLL (Fig. 2C). The loading capacity of exenatide in PLL-PEG-PLL was determined to be $\sim 5.01 \%$ (Table 1). The in vitro exenatide release from PLL-PEG-PLL was detected using dialysis. Under 0.1 M PBS (close to physiological ionic strength), sustained release of exenatide was observed, with $8.34 \%$ of exenatide released over a period of $2 \mathrm{~h}, 60.31 \%$ over a period of 1 day, and $88.74 \%$ over a period of 3 days (Fig. 2D).

\section{Cell viability}

The cytotoxicity of PLL-PEG-PLL on cardiomyocytes was monitored within 24-h culturing. PLL-PEG-PLL was atoxic at the concentrations of $\leq 50 \mu \mathrm{g} / \mathrm{mL}$ and exhibited low cytotoxicity and high relative cell viability (minimum mean was $\sim 89.2 \%$ ), even when administered at a maximum dose of $200 \mu \mathrm{g} / \mathrm{mL}$ (Fig. 2E).

The exenatide concentration in circulating blood and blood glucose level

After a single injection of $5 \mu \mathrm{g} / \mathrm{kg}$ bw exenatide, the exenatide level in circulating blood of the rats rapidly peaked to the maximum concentration $\left(C_{\max }\right)$ of $\left.678.85 \mathrm{ng} / \mathrm{mL}\right)$ at $2 \mathrm{~h}$ (time of maximum concentration, $T_{\max }$ ) and reduced to baseline level within $24 \mathrm{~h}$ (Fig. $2 \mathrm{~F}$ ). It reached the $C_{\max } 51.19 \mathrm{ng} / \mathrm{mL}$ at a $T_{\max } 6 \mathrm{~h}$ and declined to the baseline value within 3 days in exenatide/PLL-PEG-PLL rats. These data indicate that the release of exenatide in exenatide/PLL-PEG-PLL rats was substantially sustained compared with that in exenatide rats. The average blood glucose levels over time were measured in rats administered with free exenatide and exenatide-loaded polymers and compared with the normal control rats. It was found that blood glucose levels in rats injected with the free exenatide decreased within the normal range for approximately $4 \mathrm{~h}$, and then slowly went up. In contrast, administration of the exenatide/polymer complex reduced blood glucose levels to $3.85 \mathrm{mmol} / \mathrm{L}$ after $1 \mathrm{~h}$ (Fig. 3).

\section{Physiological parameters alterations}

Myocardial I/R insult reduced LVEF, $+\mathrm{dp} / \mathrm{dt}_{\max }$ and $\mathrm{BP}$, and increased LVEDP and HR. Compared with I/R group, administration of exenatide increased the LVEF, $+\mathrm{dp} / \mathrm{dt}_{\max }$, and BP levels, and reduced the LVEDP and HR values $(\mathrm{p}<0.05)$. In addition, pretreatment with exenatide/PLL-PEG-PLL significantly ameliorated the mentioned above, compared with pretreatment with free exenatide $(\mathrm{p}<0.05)$ (Fig. 3).

Serum levels of CK, $L D H, c T n T$, and GLP-1 in rats of different groups

After MI/RI, serum CK, LDH, and cTnT levels were increased, and GLP-1 level was decreased. After pretreatment with exenatide, CK, LDH, and cTnT levels were decreased, and GLP-1 level was increased compared with those in I/R group $(\mathrm{p}<0.05)$. Similarly, exenatide/ PLL-PEG-PLL polyplexes were more effective compared with free exenatide $(\mathrm{p}<0.05)$ (Figs. 4A-D).

SOD activity and MDA level in the myocardial tissue

Myocardial I/R reduced SOD activity and increased MDA level in the myocardial tissue. Compared with I/R group, preconditioning with exenatide augmented the activity of SOD whereas decreased the level of MDA $(\mathrm{p}<0.05)$. Compared with free exenatide-preconditioning, 


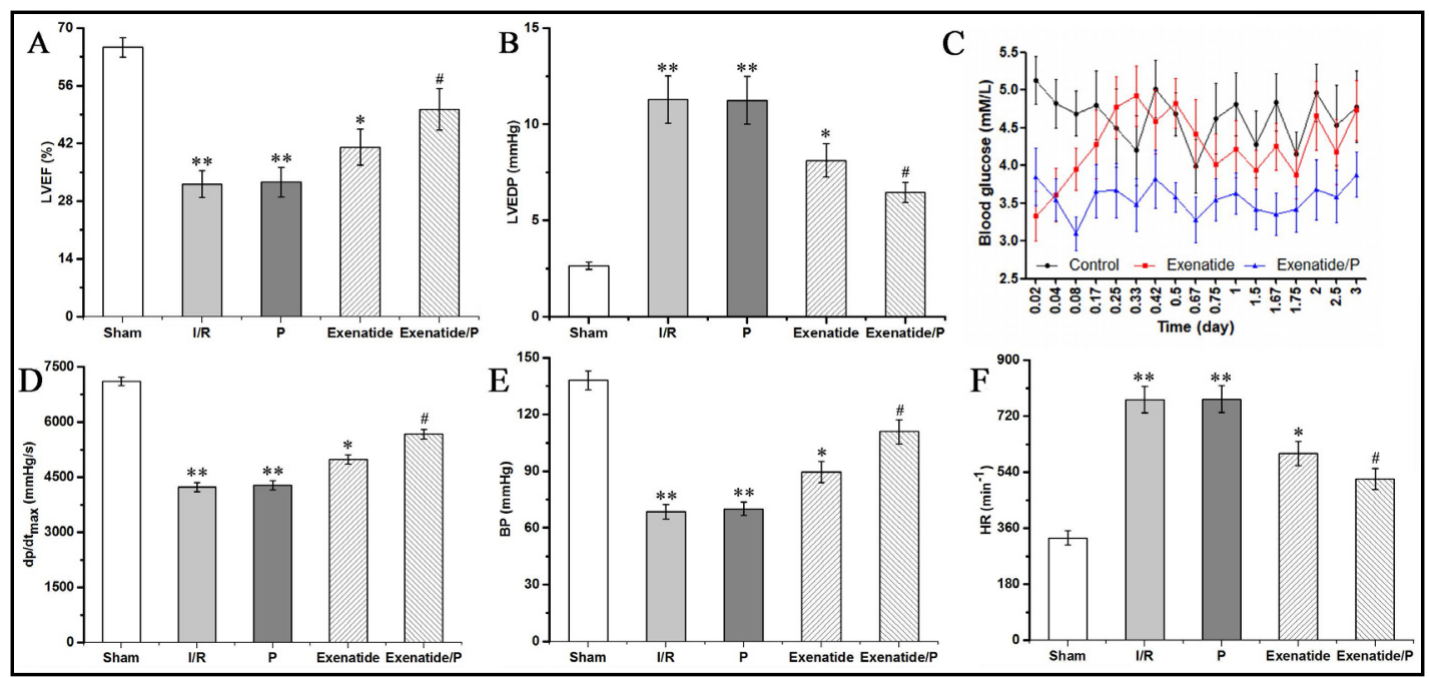

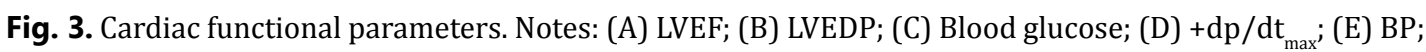
(F) HR. ${ }^{*} \mathrm{p}<0.05$, vs. I/R; ${ }^{* *} \mathrm{p}<0.01$ vs. Sham; ${ }^{\mathrm{p}}<0.05$ vs. Exenatide; $\mathrm{n}=10$.

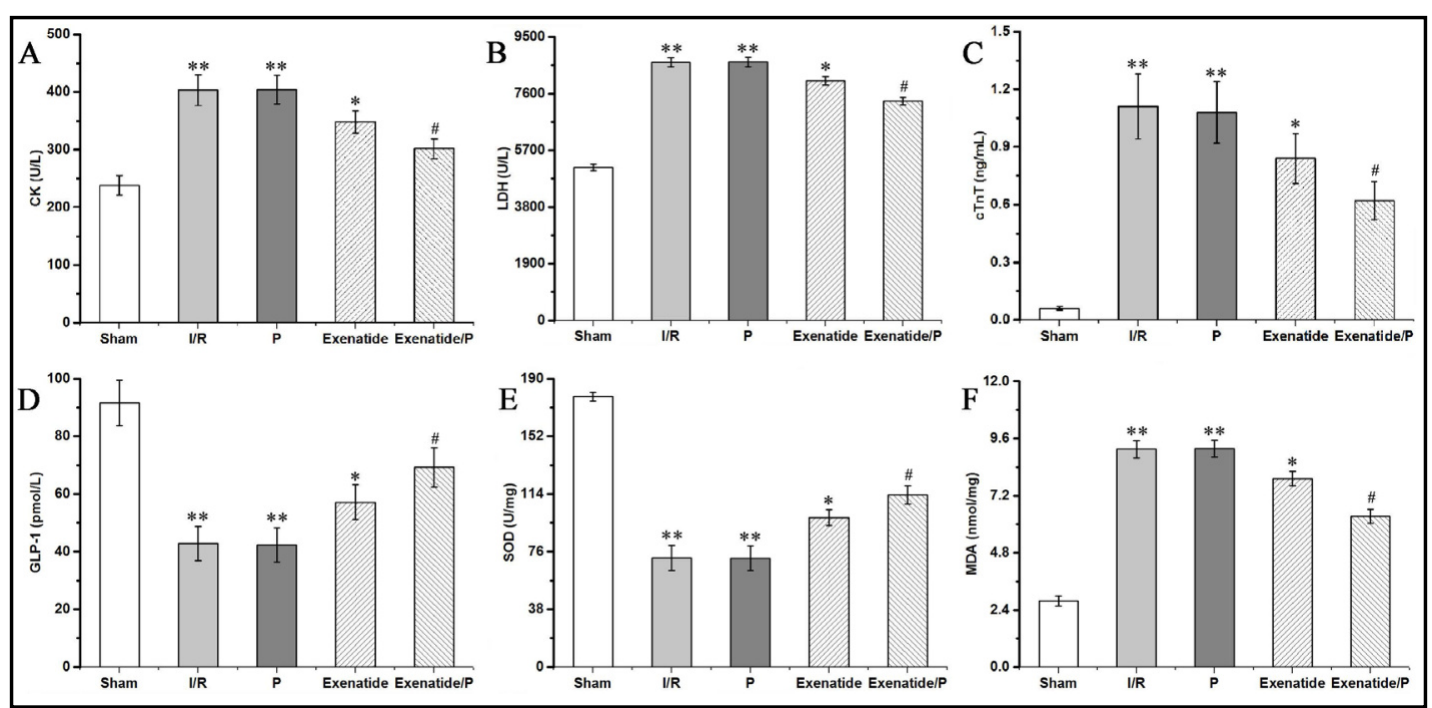

Fig. 4. Serum level of myocardial enzymes and GLP-1 and antioxidative activity in the rat myocardial tissue. Notes: (A) CK; (B) LDH; (C) cTnT; (D) GLP-1; (E) SOD; (F) MDA. " $p<0.05$, vs. I/R; ${ }^{* *} \mathrm{p}<0.01$ vs. Sham; ${ }^{*} \mathrm{p}<0.05$ vs. Exenatide; $\mathrm{n}=10$.

exenatide/PLL-PEG-PLL-pretreatment markedly improved SOD activity and decreased MDA level $(\mathrm{p}<0.05)$ (Figs. 4E-F).

\section{Histopathological changes of the myocardial tissue}

Light microscopy showed several hemorrhagic lesions and myocardial edemas in intermuscular spaces after the I/R surgery. There were obvious cardiomyocyte edema (myocardial cytoplasmic vacuole formation), apoptosis, necrosis, dissolution, intermuscular hemorrhage, and wave-twisted deformation of cardiac muscle fibers in I/R group. These histopathological alterations were markedly attenuated in exenatide/PLL-PEG-PLLpretreatment group and moderately alleviated in exenatide-preconditioning group $(\mathrm{p}<0.05)$ (Fig. 5). 


\section{Kidney Blood Pressure Research}

GLP-1R expression in the myocardial tissue

As shown in Fig. 6, MI/RI downregulated the expression of GLP-1R in the myocardial tissue. Administration of exenatide upregulated GLP-1R expression, compared with that in I/R group ( $\mathrm{p}<0.05)$. Compared with preconditioning with free exenatide, administration of exenatide/PLL-PEG-PLL markedly increased GLP-1R expression $(\mathrm{p}<0.05)$.

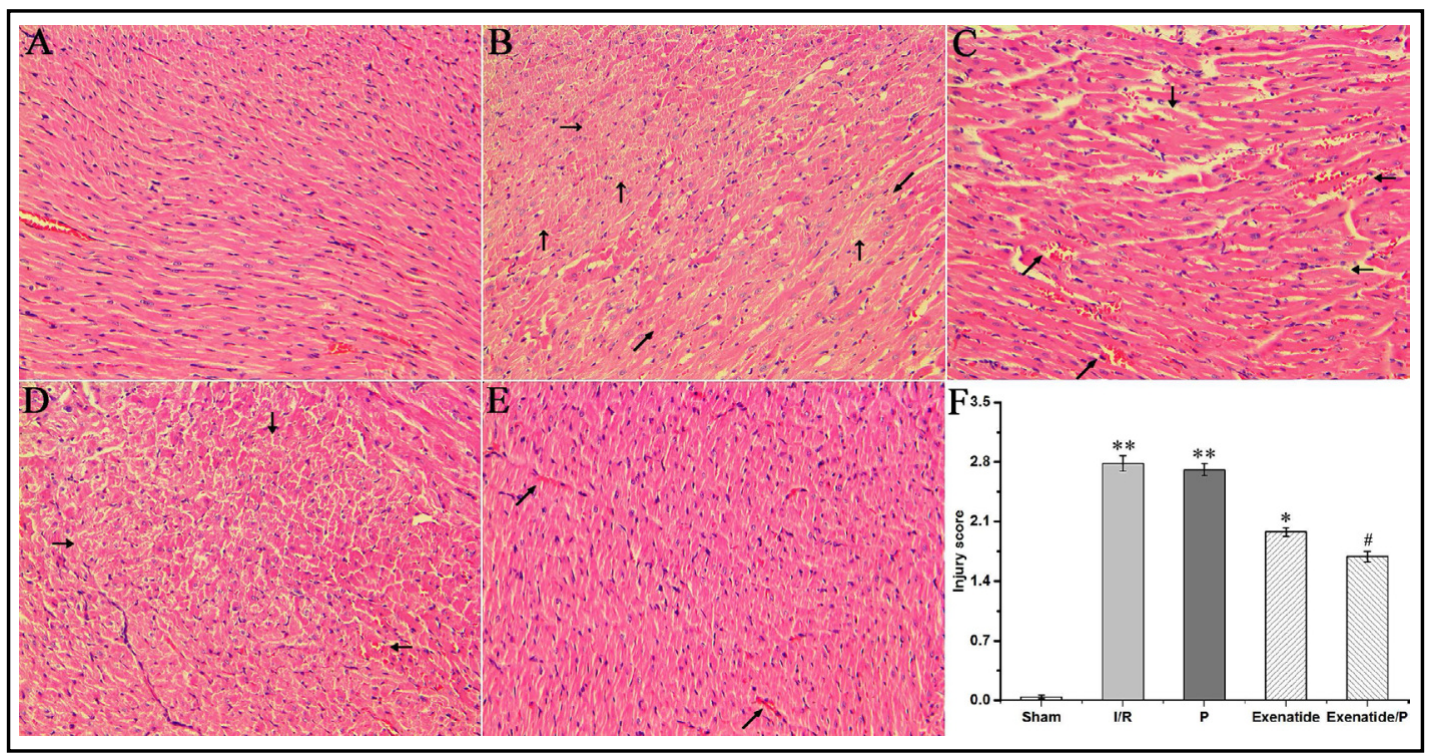

Fig. 5. Histopathologic alterations in the rat myocardial tissue. Notes: (A) Sham; (B) I/R; (C) P; (D) Exenatide; (E) Exenatide/P; (F) Injury score. Black arrows represent cell damage and interstitial bleeding. The magnification is $\times 200{ }^{*} \mathrm{p}<0.05$, vs. I/R; ${ }^{* *} \mathrm{p}<0.01$ vs. Sham; ${ }^{\#} \mathrm{p}<0.05$ vs. Exenatide; $\mathrm{n}=10$.

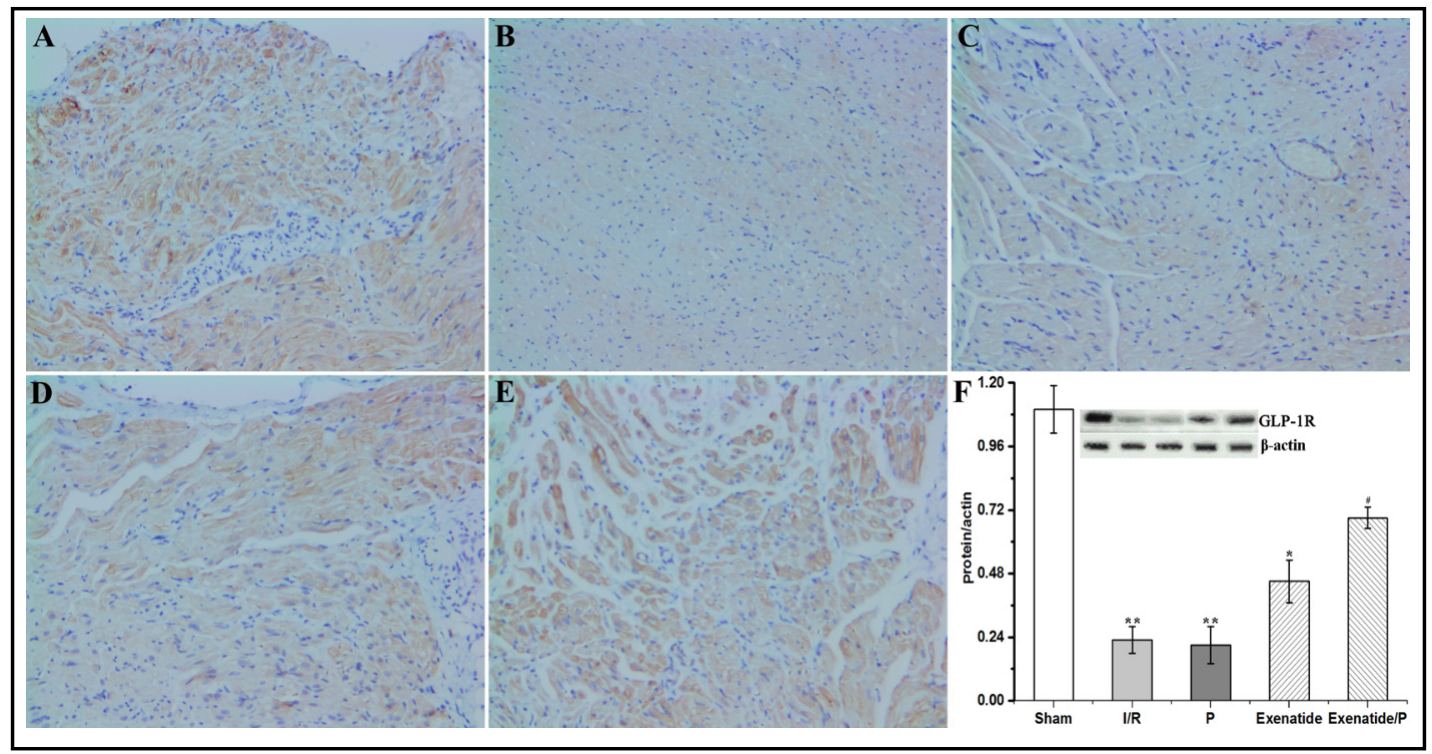

Fig. 6. GLP-1R expression in the rat myocardial tissue by IHC and Western blotting. Notes: (A) Sham; (B) I/R; (C) P; (D) Exenatide; (E) Exenatide/P; (F) Western blotting. The magnification is $\times 200 .{ }^{*} \mathrm{p}<0.05$, vs. I/R; ${ }^{* *} \mathrm{p}<0.01$ vs. Sham; ${ }^{\mathrm{p}}<0.05$ vs. Exenatide; $\mathrm{n}=10$. 


\section{Kidney Blood Pressure Research}

Kidney Blood Press Res 2018;43:1273-1284

\begin{tabular}{l|l}
\hline DOI: 10.1159/000492409 & (C) 2018 The Author(s). Published by S. Karger AG, Base
\end{tabular}

Published online: 3 August, 2018

www.karger.com/kb

Zhang et al.: Exenatide Nanoparticles For MI/RI

\section{Discussion}

In this study, we developed an exenatide nanocarrier PLL-PEG-PLL to prolong the in vivo half-life of exenatide, demonstrating that pretreatment with exenatide or exenatide/ PLL-PEG-PLL NPs was able to alleviate MI/RI. The block copolymer is composed of two brush-like PLL block polymers and a linear PEG block polymer, wherein the negatively charged exenatide combines with the positively charged PLL brush block polymers through electrostatic interactions at physiological $\mathrm{pH}$ ( $\mathrm{pH}$ 7.4). The loaded exenatide can be released in a sustained manner, thus significantly improving the bioavailability of free exenatide. Exenatide is known as a synthetic version of exendin-4 with a 39-amino-acid peptide as an insulin secretagogue to exert the glucoregulatory effects [38]. It is often used for patients whose diabetes is not well-controlled by other oral medications which are injected subcutaneously twice per day [39]. Exenatide can also be used to protect the myocardial function $[40,41]$. However, the overall role of exenatide in MI/RI is unclear, and there are few studies focusing on the application of an exenatide-loaded nanocarrier for the treatment of MI/RI. In the present study, we delineated an important myocardial preservative role of exenatide in MI/RI through exenatide-loaded nanocarrier PLL-PEG-PLL preconditioning.

I/R injury is a tissue damage occurring when blood supply returns to the tissue after a period of ischemia, wherein the absence of oxygen and nutrients from blood during the ischemic period creates a condition in which the restoration of circulation results in oxidative injury and inflammation through the induction of oxidative stress along with restoration of the normal function $[42,43]$. Although the functional consequences of depriving a tissue of its blood supply have been appreciated for many years, the cardiovascular diseases initiated by local or systemic tissue ischemia remain the leading cause of death worldwide. Oxidative stress, reflecting an imbalance between the ability of the biological system and the systemic manifestation of reactive oxygen species to repair the resulting damage, can trigger cell apoptosis and even necrosis. SOD is an important antioxidant defense protein in nearly all living cells exposed to oxygen, whereby it can catalyze the dismutation of the superoxide radical into hydrogen peroxide or either ordinary molecular oxygen $[44,45]$. The results described in this study demonstrate that the increased level of myocardial I/R-induced oxidative stress was significantly inhibited by the upregulation of SOD and downregulation of MDA after pretreatment with exenatide or exenatide/PLL-PEG-PLL NPs. Meanwhile, preconditioning with exenatide or exenatide/PLL-PEG-PLL polyplexes recovered the abnormity of cardiac functional parameters (LVEF, LVEDP, $+\mathrm{dp} / \mathrm{dt}_{\text {max }^{\prime}}$ BP, and HR) and myocardial enzymes (CK, $\mathrm{LDH}$, and cTnT) to a certain extent. Therefore, exenatide/PLL-PEG-PLL may potentially be useful for the treatment of I/R-induced myocardial injury by modulating the status of oxidative stress. Exenatide is associated with a modest increase in BP and a slight reduction in HR after cardiac I/R; yet the relevant mechanism remains unclear at present [46], and further investigations to explore underlying mechanism are warranted.

GLP-1 is a thirty-amino acid long peptide incretin hormone deriving from the tissuespecific posttranslational processing of the proglucagon gene. It was originally found to increase insulin synthesis and secretion. A recent study showed that GLP-1 played a cardioprotective role through an antioxidant mechanism by decreasing fatty acid oxidation and increasing glucose oxidation $[47,48]$. In addition, its receptor was found to be extensively expressed in the vascular tree in normotensive rats [49]. It was found in the present study that pretreatment with exenatide and exenatide/PLL-PEG-PLL could raise the levels of BP, $\mathrm{LVEF}$, and $+\mathrm{dp} / \mathrm{dt}_{\text {max }}$, and reduce LVEDP and HR through improving GLP-1 and its receptor expression, suggesting that the antioxidative and blood flow-regulatory effects of GLP-1R are important mechanisms underlying myocardial preservation effect of exenatide in MI/RI. 


\section{Kidney Blood Pressure Research}

Zhang et al.: Exenatide Nanoparticles For MI/RI

\section{Conclusion}

Preconditioning with exenatide/PLL-PEG-PLL exerted a protective effect against myocardial I/R insult by reducing myocardial damage, decreasing LVEDP, HR, CK, LDH, cTnT, and MDA levels, increasing LVEF, $+\mathrm{dp} / \mathrm{dt}_{\text {max }^{\prime}}$ and BP, and regulating the GLP-1R expression and SOD activity. The use of the block copolymer PLL-PEG-PLL as an exenatide nanocarrier significantly enhanced this protective effect as a result of sustained release and prolonged half-life in circulating blood in vivo, thus enhancing the bioactivity of exenatide. A further study of our research team is underway to explore the underlying mechanisms of the protective effect of exenatide/PLL-PEG-PLL polyplexes in MI/RI.

\section{Acknowledgements}

The authors greatly appreciate the editors and the anonymous peer reviewer for their critical reading and insightful comments, which have improved our manuscript substantially.

This study was supported by grants from the Science and Technology Planning Project of Jiaxing (2017AY33056, 2018AY33083). The sponsors of the study had no role in study design, data collection, data analysis, data interpretation, or manuscript writing.

We appreciated Prof. Dr. Shunxing Zhang (The Second Military Medical University, Shanghai, China) for his careful English language editing.

\section{Disclosure Statement}

The authors report no conflict of interest in this work.

\section{References}

1 Murray CJ, Lopez AD: Alternative projections of mortality and disability by cause 1990-2020: Global Burden of Disease Study. Lancet 1997;349:1498-1504.

- 2 Hu B, Xu G, Zheng Y, Tong F, Qian P, Pan X, Zhou X, Shen R: Chelerythrine Attenuates Renal Ischemia/ Reperfusion-induced Myocardial Injury by Activating CSE/H2S via PKC/NF- $\kappa B$ Pathway in Diabetic Rats. Kidney Blood Press Res 2017;42:379-388.

-3 Guo JJ, Xu FQ, Li YH, Li J, Liu X, Wang XF, Hu LG, An Y: Alginate oligosaccharide alleviates myocardial reperfusion injury by inhibiting nitrative and oxidative stress and endoplasmic reticulum stress-mediated apoptosis. Drug Des Devel Ther 2017;11:2387-2397.

-4 Pei H, Yu Q, Xue Q Guo Y, Sun L, Hong Z, Han H, Gao E, Qu Y, Tao L: Notch1 cardioprotection in myocardial ischemia/reperfusion involves reduction of oxidative/nitrative stress. Basic Res Cardiol 2013;108:373.

-5 Garcia-Dorado D, Ruiz-Meana M, Inserte J, Rodriguez-Sinovas A, Piper HM: Calcium-mediated cell death during myocardial reperfusion. Cardiovasc Res 2012;94:168-180.

6 Godar RJ, Ma X, Liu H, Murphy JT, Weinheimer CJ, Kovacs A, Crosby SD, Saftig P, Diwan A: Repetitive stimulation of autophagy-lysosome machinery by intermittent fasting preconditions the myocardium to ischemia-reperfusion injury. Autophagy 2015;11:1537-1560.

7 Yang Y, Zhao L, Ma J: Penehyclidine hydrochloride preconditioning provides cardiac protection in a rat model of myocardial ischemia/reperfusion injury via the mechanism of mitochondrial dynamics mechanism. Eur J Pharmacol 2017;813:130-139.

$>8$ Donato M, Evelson P, Gelpi RJ: Protecting the heart from ischemia/reperfusion injury: an update on remote ischemic preconditioning and postconditioning. Curr Opin Cardiol 2017;32:784-790.

-9 Yang F, Li T, Dong Z, Mi R: MicroRNA-410 is involved in mitophagy after cardiac ischemia/reperfusion injury by targeting high-mobility group box 1 protein. J Cell Biochem 2018;119:2427-2439. 


\section{Kidney \\ Blood Pressure Research}

Zhang et al.: Exenatide Nanoparticles For MI/RI

10 Barnett AH: New treatments in type 2 diabetes: a focus on the incretin-based therapies. Clin Endocrinol (Oxf) 2009;70:343-353.

11 Bao W, Holt LJ, Prince RD, Jones GX, Aravindhan K, Szapacs M, Barbour AM, Jolivette LJ, Lepore JJ, Willette RN, DeAngelis E, Jucker BM: Novel fusion of GLP-1 with a domain antibody to serum albumin prolongs protection against myocardial ischemia/reperfusion injury in the rat. Cardiovasc Diabetol 2013;12:148.

12 Grieve DJ, Cassidy RS, Green BD: Emerging cardiovascular actions of the incretin hormone glucagon-like peptide-1: potential therapeutic benefits beyond glycaemic control? Br J Pharmacol 2009;157:1340-1351.

$>13$ Li Y, Perry T, Kindy MS, Harvey BK, Tweedie D, Holloway HW, Powers K, Shen H, Egan JM, Sambamurti K, Brossi A, Lahiri DK, Mattson MP, Hoffer BJ, Wang Y, Greig NH: GLP-1 receptor stimulation preserves primary cortical and dopaminergic neurons in cellular and rodent models of stroke and Parkinsonism. Proc Natl Acad Sci U S A 2009;106:1285-1290.

14 Rachmany L, Tweedie D, Li Y, Rubovitch V, Holloway HW, Miller J, Hoffer BJ, Greig NH, Pick CG: Exendin-4 induced glucagon-like peptide-1 receptor activation reverses behavioral impairments of mild traumatic brain injury in mice. Age (Dordr) 2013;35:1621-1636.

15 Avogaro A: Glucagon like peptide-1 and the cardiovascular system: pathophysiological mechanisms. G Ital Cardiol (Rome) 2010;11:18S-25S.

16 Ravassa S, Zudaire A, Carr RD, Diez J: Antiapoptotic effects of GLP-1 in murine HL-1 cardiomyocytes. Am J Physiol Heart Circ Physiol 2011;300:H1361-1372.

17 Bose AK, Mocanu MM, Carr RD, Yellon DM: Myocardial ischaemia-reperfusion injury is attenuated by intact glucagon like peptide-1 (GLP-1) in the in vitro rat heart and may involve the p70s6K pathway. Cardiovasc Drugs Ther 2007;21:253-256.

$\checkmark 18$ Huisamen B, Genade S, Lochner A: Signalling pathways activated by glucagon-like peptide-1 (7-36) amide in the rat heart and their role in protection against ischaemia. Cardiovasc J Afr 2008;19:77-83.

19 Zheng A, Cao L, Qin S, Chen Y, Li Y, Zhang D: Exenatide Regulates Substrate Preferences Through the p38y MAPK Pathway After Ischaemia/Reperfusion Injury in a Rat Heart. Heart Lung Circ 2017;26:404-412.

20 Woo JS, Kim W, Ha SJ, Kim JB, Kim SJ, Kim WS, Seon HJ, Kim KS: Cardioprotective effects of exenatide in patients with ST-segment-elevation myocardial infarction undergoing primary percutaneous coronary intervention: results of exenatide myocardial protection in revascularization study. Arterioscler Thromb Vasc Biol 2013;33:2252-2260.

-21 Chang G, Liu J, Qin S, Jiang Y, Zhang P, Yu H, Lu K, Zhang N, Cao L, Wang Y, Li Y, Zhang D: Cardioprotection by exenatide: A novel mechanism via improving mitochondrial function involving the GLP-1 receptor/cAMP/ PKA pathway. Int J Mol Med 2018;41:1693-1703.

-22 Tong F: Preparation of exenatide-loaded linear poly(ethylene glycol)-brush poly(l-lysine) block copolymer: potential implications on diabetic nephropathy. Int J Nanomedicine 2017;12:4663-4678.

23 Hua SH, Li YY, Liu Y, Xiao W, Li C, Huang FW, Zhang XZ, Zhuo RX: Self-Assembled Micelles Based on PEGPolypeptide Hybrid Copolymers for Drug Delivery. Macromol Rapid Commun 2010;31:81-86.

-24 Hu N, Yin JF, Ji Z, Hong Y, Wu P, Bian B, Song Z, Li R, Liu Q, Wu F: Strengthening Gastric Cancer Therapy by Trastuzumab-Conjugated Nanoparticles with Simultaneous Encapsulation of Anti-MiR-21 and 5-Fluorouridine. Cell Physiol Biochem 2017;44:2158-2173.

25 Chen X, Sun J, Li H, Wang H, Lin Y, Hu Y, Zheng D: Curcumin-Loaded Nanoparticles Protect Against Rhabdomyolysis-Induced Acute Kidney Injury. Cell Physiol Biochem 2017;43:2143-2154.

-26 He X, Yang L, Wang M, Zhuang X, Huang R, Zhu R, Wang S: Targeting the Endocannabinoid/CB1 Receptor System For Treating Major Depression Through Antidepressant Activities of Curcumin and DexanabinolLoaded Solid Lipid Nanoparticles. Cell Physiol Biochem 2017;42:2281-2294.

27 Guo M, Li D, Shen H, Jin B, Ren Y, Li M, Xing Y: Leptin-Sensitive JAK2 Activation in the Regulation of Tau Phosphorylation in PC12 Cells. Neurosignals 2016;24:88-94.

28 Zheng Y, Wang J, Li D, Guo M, Zhen M, Chang Q: Wnt/ $\beta$-Catenin Signaling Pathway Against Abeta Toxicity in PC12 Cells. Neurosignals 2016;24:40-47.

29 Xu G, Gu H, Hu B, Tong F, Liu D, Yu X, Zheng Y, Gu J: PEG-b-(PELG-g-PLL) nanoparticles as TNF- $\alpha$ nanocarriers: potential cerebral ischemia/reperfusion injury therapeutic applications. Int J Nanomedicine 2017;12:2243-2254. 


\section{Kidney \\ Blood Pressure Research}

-30 Manne N, Arvapalli R, Graffeo VA, Bandarupalli VVK, Shokuhfar T, Patel S, Rice KM, Ginjupalli GK, Blough ER: Prophylactic Treatment with Cerium Oxide Nanoparticles Attenuate Hepatic Ischemia Reperfusion Injury in Sprague Dawley Rats. Cell Physiol Biochem 2017;42:1837-1846.

31 Kang Y, Liu J, Song B, Feng X, Ou L, Wei L, Lai X, Shao L: Potential Links between Cytoskeletal Disturbances and Electroneurophysiological Dysfunctions Induced in the Central Nervous System by Inorganic Nanoparticles. Cell Physiol Biochem 2016;40:1487-1505.

32 Wang C, Blough E, Dai X, Olajide O, Driscoll H, Leidy JW, July M, Triest WE, Wu M: Protective Effects of Cerium Oxide Nanoparticles on MC3T3-E1 Osteoblastic Cells Exposed to X-Ray Irradiation. Cell Physiol Biochem 2016;38:1510-1519.

-33 Ding Y, Vaziri ND, Coulson R, Kamanna VS, Roh DD: Effects of simulated hyperglycemia, insulin, and glucagon on endothelial nitric oxide synthase expression. Am J Physiol Endocrinol Metab 2000;279:E1117.

-34 Hu B, Tong F, Xu L, Shen Z, Yan L, Xu G, Shen R: Role of Calcium Sensing Receptor in Streptozotocin-Induced Diabetic Rats Exposed to Renal Ischemia Reperfusion Injury. Kidney Blood Press Res 2018;43:276-286.

-35 Shen X, Hu B, Xu G, Chen F, Ma R, Zhang N, Liu J, Ma X, Zhu J, Wu Y, Shen R: Activation of Nrf2/HO-1 Pathway by Glycogen Synthase Kinase-3 $\beta$ Inhibition Attenuates Renal Ischemia/Reperfusion Injury in Diabetic Rats. Kidney Blood Press Res 2017;42:369-378.

-36 Hu B, Wu Y, Liu J, Shen X, Tong F, Xu G, Shen R: GSK-3beta Inhibitor Induces Expression of Nrf2/TrxR2 Signaling Pathway to Protect against Renal Ischemia/Reperfusion Injury in Diabetic Rats. Kidney Blood Press Res 2016;41:937-946.

-37 Hu B, Wu T, Zhao Y, Xu G, Shen R, Chen G: Physiological Signatures of Dual Embryonic Origins in Mouse Skull Vault. Cell Physiol Biochem 2017;43:2525-2534.

38 Bomba M, Granzotto A, Castelli V, Massetti N, Silvestri E, Canzoniero LMT, Cimini A, Sensi SL: Exenatide exerts cognitive effects by modulating the BDNF-TrkB neurotrophic axis in adult mice. Neurobiol Aging 2017;64:33-43.

-39 Yang Y, Zhou X, Gao S, Lin H, Xie Y, Feng Y, Huang K, Zhan S: Evaluation of Electronic Healthcare Databases for Post-Marketing Drug Safety Surveillance and Pharmacoepidemiology in China. Drug Saf 2018;41:125137.

40 Darwesh AM, El-Azab MF, Abo-Gresha NM, El-Sayed NM, Moustafa YM: Cardioprotective Mechanisms of Exenatide in Isoprenaline-induced Myocardial Infarction: Novel Effects on Myocardial alpha-Estrogen Receptor Expression and IGF-1/IGF-2 System. J Cardiovasc Pharmacol 2018;71:160-173.

41 Mentz RJ, Bethel MA, Gustavson S, Thompson VP, Pagidipati NJ, Buse JB, Chan JC, Iqbal N, Maggioni AP, Marso SP, Ohman P, Poulter N, Ramachandran A, Zinman B, Hernandez AF, Holman RR: Baseline characteristics of patients enrolled in the Exenatide Study of Cardiovascular Event Lowering (EXSCEL). Am Heart J 2017;187:1-9.

42 Carden DL, Granger DN: Pathophysiology of ischaemia-reperfusion injury. J Pathol 2000;190:255-266.

-43 Hu B, Wu Y, Tong F, Liu J, Shen X, Shen R, Xu G: Apocynin Alleviates Renal Ischemia/Reperfusion Injury Through Regulating the Level of Zinc and Metallothionen. Biol Trace Elem Res 2017;178:71-78.

44 Hayyan M, Hashim MA, AlNashef IM: Superoxide Ion: Generation and Chemical Implications. Chem Rev 2016;116:3029-3085.

45 Chen Y, Zhao L, Jiang S, Hu Z, Hu B, Tong F, Shen R: Cystathionine y-Lyase is Involved in the Renoprotective Effect of Brief and Repeated Ischemic Postconditioning after Renal Ischemia/Reperfusion Injury in Diabetes Mellitus. Transplant Proc 2018;50:1549-1557.

-46 Sun F, Wu S, Guo S, Yu K, Yang Z, Li L, Zhang Y, Quan X, Ji L, Zhan S: Impact of GLP-1 receptor agonists on blood pressure, heart rate and hypertension among patients with type 2 diabetes: A systematic review and network meta-analysis. Diabetes Res Clin Pract 2015;110:26-37.

47 Al Batran R, Almutairi M, Ussher JR: Glucagon-like peptide-1 receptor mediated control of cardiac energy metabolism. Peptides 2018;100:94-100.

48 Oh YS, Jun HS: Effects of Glucagon-Like Peptide-1 on Oxidative Stress and Nrf2 Signaling. Int J Mol Sci 2017; DOI:10.3390/ijms19010026.

49 Ronn J, Jensen EP, Wewer Albrechtsen NJ, Holst JJ, Sorensen CM: Glucagon-like peptide-1 acutely affects renal blood flow and urinary flow rate in spontaneously hypertensive rats despite significantly reduced renal expression of GLP-1 receptors. Physiol Rep 2017; DOI:10.14814/phy2.13503. 